\title{
Spice Plants and the Bioavailability of Nutrients
}

\author{
Monica Butnariu* \\ Banat's University of Agricultural Sciences and Veterinary Medicine, "King Michael I of Romania", Timis, Romania
}

\section{Executive Summary}

The consumption of a particular food or beverage does not mean automatically that all the nutrients are bioequivalence or bioavailability for the human body, where they should be used or stored. Sometimes they just pass by through the gastrointestinal tract without being assimilated, and sometimes they are broken down immediately by the liver and excreted by the kidneys. Nutrients have to go through a series of obstacles, starting from the moment they are ingested and until used or stored. The bioavailability of a particular nutrient refers to its ability to go through one or more of these obstacles, so that it gets absorbed by the body and become available for use or storage.

\section{Why is Bioavailability so Important?}

There are many factors that can large or reduced bioavailability of nutrients, many of them associated with aspects of style life in modern society. Meals taken on the run, consumption of processed foods and other eating habits of this kind may contribute to inflammation and damage the gastrointestinal wall in varying degrees, thus preventing proper absorption of nutrients. When food passes through the gastrointestinal tract too fast, there is no adequate absorption and a great deal of nutrients they get out of the body. Many of the foods we eat they come from poor soils of nutrients as a result of agricultural practices. Foods are, therefore, deficient from the beginning, that is (nutrients) why it is all the more important for the body to be able to take everything he can of what we consume. Other factors that may influence bioavailability include deficient digestion of digestive enzymes in the gastrointestinal tract, consuming an inappropriate combination and food many others [1].

\section{Spice Plants}

The modern term "bio stimulating plant" refers to those plants (or aromatic plants) that are bio-intensifying the availability of other substances when used in conjunction with them. These are normally added in small quantities and do not exhibit significant therapeutic effects if used as such. The concept of spice plants has been used for centuries in all herbal medicinal traditions around the world. Among Western professionals in the field of herbal medicine, the term "activator" or "catalyst" is used to describe the role of stimulating the bio-availability of these plants, whereas traditional Chinese medicine uses the term "harmonizing" to describe the same action. In addition, the same plants are used for the same purpose in many culinary traditions for exactly the same reasons. Spice plants have been found to enhance gastrointestinal tract absorption through various mechanisms such as increased blood volume to the intestinal gastrointestinal area and stimulation of enzymes and transporters in the membranes, which facilitates the absorption of nutrients [2]. In addition, it has been shown to reduce the activity of liver enzymes that would normally decompose and eliminate these nutrients. Here are some common plants that have been found to stimulate the bio availability of many types of nutrients, such as vitamins, minerals, amino acids, antioxidants and phytonutrients:

\section{Black pepper (Piper nigrum)}

Piperine, a unique phytochemical extract extracted from Black Pepper, has been found to increase the bioavailability of a variety of nutrients: vitamins; aminoacids; minerals, etc and major compounds oil are a-pinene, b-pinene, limonene, myrcene, sabinene, camphene, a-thujone, piperitone, caryophyllene, pinocarveol, p-cymene, b-bisabolene, a-phellandrene, b-farnesene, a-terpinene and linalool. Plant compounds whose bioavailability is potent boswellic acid (Boswellia serrata); ginsenoside (Gingko biloba); withanolide (Withania somnifera); curcuminoids (Curcuma longa); pycnogenol (Pinus pinaster) [3].

\section{Ginger (Zingiber officinalis)}

A ginger extract has been found to stimulate the bioavailability of a variety of nutrients and, in many cases, in combination with Piperin, an increase in the percentage of biostimulation is observed [4]. Plant compounds whose bioavailability is potent:

Echinacea: It contains the classes of compounds: phenylpropanoids (echinacoside, des-rhamnosylverbascoside and 6-O-caffeoylechinacoside, cynarin, cichoric acid, caftaric, chlorogenic and isochlorogenic acids), flavonoids (luteolin, kaempferol, quercetin, quercetagetin, apigenin, isorhamnetin) terpenoid compounds (borneol, bornyl acetate, pentadeca-8-(Z)-en-2-one, germacrene D, caryophyllene, pentadeca-(1.8-Z)-diene, 1-pentadecene, ketoalkynes and ketoalkenes, and caryophyllene epoxide) polyacetylenes (trideca-1-en-3,5,7,9,10-pentayne and ponticaepoxyde); alkylamides (echinacein=dodeca-(2E, 6Z, 8E, 10E)- tetraenoic acid, isobutylamides of C11-C16 straight-chain fatty acids with olefinic or acetylenic bonds, alkamide is a mixture of isomeric dodeca 2,4,8,10-tetraenoic acid isobutylamides); alkaloids (sotussilagine and tussilagine); polysaccharides (inulin, arabinorhamnogalactans, heteroxylans, methylglucuroarabinoxylan, acidic arabinorhamnogalactan [5];

Tinospora cordifolia: It contains: columbin, tinosporaside, jatrorhizine, palmatine, berberine, tembeterine, tinocordifolioside, phenylpropene disaccharides, choline, tinosporic acid, tinosporal, and tinosporon [6];

Picrorhiza kurroa: Which contains: picroside I, picroside II, picroside III, picroside IV, kutkoside, pikuroside and flavonoids like apocynin and vanillic acid [7];

*Corresponding author: Monica Butnariu, Professor, Habilitated Doctor, Chemist Chemistry \& Biochemistry Discipline, Banat's University of Agricultural Sciences and Veterinary Medicine, "King Michael I of Romania", Timis, Romania, Tel: 918066628801; E-mail: monicabutnariu@yahoo.com

Received April 29, 2018; Accepted May 01, 2018; Published May 07, 2018

Citation: Butnariu M (2018) Spice Plants and the Bioavailability of Nutrients. J Bioequiv Availab 10: e85. doi: 10.4172/0975-0851.1000e85

Copyright: (ㅇ 2018 Butnariu M. This is an open-access article distributed under the terms of the Creative Commons Attribution License, which permits unrestricted use, distribution, and reproduction in any medium, provided the original author and source are credited. 
Andrographis paniculate: With flavonoids: 5,5'-dihydroxy7,8,2'-trimetroxyflavone, 5-hydroxy-7,8,2',6'-tetramethoxyflavone, 5,3'-dihydroxy-7,8,4'-trimethoxyflavone, 2'-hydroxy-5,7,8trimethoxyflavone, 5-hydroxy-7,8,2',3', 4'-pentamethoxyflavone, wightin, 5,2',6'-trihydroxy-7-methoxyflavone 2'-O-beta-Dglucopyranoside, 5,7,8,2'-tetramethoxyflavone, 5-hydroxy-7,8dimethoxyflavanone, 5-hydroxy-7,8-dimethoxyflavone, 5,2'-dihydroxy7,8-dimethoxyflavone, 5-hydroxy-7,8,2',5'-tetramethoxyflavone, 5-hydroxy-7,8,2',3'-tetramethoxyflavone, 5-hydroxy-7,8,2'trimethoxyflavone, 5,4'-dihydroxy-7,8,2',3'-tetramethoxyflavone, dihydroneobaicalein, andrographidine A, andrographidine B, andrographidine $\mathrm{C}$ and 5,2'-dihydroxy-7,8-dimethoxyflavone 2'-O-beta-D-glucopyranoside; three diterpenoids: andrograpanin, neoandrographolide and andrographolide; two phenylpropanoids: trans-cinnamic acid and 4-hydroxy-2-methoxycinnamaldehyde; and oleanolic acid, beta-sitosterol and beta-daucosterol [8];

Emblica ribes: With: embelin, volatile oil, fixed oil, resin, tannin, christembine (alkaloid), phenolic acids like caffeic acid, vanillic acid, chrorogenic acid, cinnamic acid, o-cumaric acid [9];

Asparagus racemosus: With: inulin, asparagusic acid, and eight fructo-oligosaccharides, officinalisnin-I and officinalisnin-II, b-sitosterol, sarsasapogenin, asparagamine A [10];

Withania somnifera: Biologically active chemical constituents are alkaloids (isopellertierine, anferine), steroidal lactones (withanolides, withaferins), saponins containing an additional acyl group (sitoindoside VII and VIII), and withanoloides with a glucose at carbon 27 (sitonidoside XI and X) [11].

\section{Cumin (Cuminum cyminum)}

Phytochemical analysis showed that Cuminum cyminum contained compounds: alkaloid, anthraquinone, coumarin, flavonoid, glycoside, protein, resin, saponin, tannin and steroid. The major compounds (in the cumin essential oil were cumin aldehyde, tetradecene, $\gamma$-terpenene, $\beta$-ocimene, $p$-mentha-2-en-ol, $\alpha$-terpinyl acetate, $\alpha$-terpinolene, lmonine, myrcene, $\beta$-pinene, $\alpha$-pinene, 2 -caren-10-al, trans-carveol and myrtenal) has been found to stimulate the bioavailability of a variety of nutrients, and in many cases, when Piperin was added, an increase in biostimulation rates was observed [12].

\section{Caraway (Carum carvi)}

Or meridian fennel, Persian cumin, chemical composition is represented by compounds whose properties of bioequivalence and bioavailability are amplified are myrcene; limonene; $\alpha$-terpinolene; trans limonene oxide; trans dihydro carvone; trans carveol; carvone; perilla alcohol; carvacrol; $\beta$-caryophyllene, etc. [13].

Many research studies carried out on spice plants have shown that isolated ingredients of different plants potentiate the bioavailability of pharmaceuticals. The mechanisms that make this possible could theoretically be applied to nutrients, but this still remains to be proven.

\section{Conclusions and Remarks}

In the above-mentioned studies, they tested only for a restricted nutrient segment using a single compound from a plant as a biostimulating agent. Besides these there are many other well-known nutrients that have not been tested and many other plant compounds, as well as synergistic combinations of the compounds of one of the plants, which can theoretically have effects on bioavailability. Although many plants have great potential for biostimulation, there is a need for studies to prove this and scientifically. Until then, however, there is no reason why these plants cannot be used, especially since they have been used for centuries, are safe and very easy to obtain. In fact, they are among the most used ingredients in culinary and medicinal traditions all over the world.

\section{References}

1. Kumari M, Platel K (2017) Effect of sulfur-containing spices on the bioaccessibility of trace minerals from selected cereals and pulses. J Sci Food Agric 97: 2842-2848.

2. Liju VB, Jeena K, Kumar D, Maliakel B, Kuttan R, et al. (2015) Enhanced bioavailability and safety of curcumagalactomannosides as a dietary ingredient. Food Funct 6: 276-286.

3. Hwang KS, Kim YK, Park KW, Kim YT (2017) Piperolein B and piperchabamide $\mathrm{D}$ isolated from black pepper (Piper nigrum L.) as larvicidal compounds against the diamondback moth (Plutella xylostella). Pest Manag Sci 73:1564-1567.

4. Pang X, Cao J, Wang D, Qiu J, Kong F (2017) Identification of Ginger (Zingiber officinale Roscoe) Volatiles and Localization of Aroma-Active Constituents by GC-Olfactometry. J Agric Food Chem 65: 4140-4145.

5. Moazami Y, Gulledge TV, Laster SM, Pierce JG (2015) Synthesis and biological evaluation of a series of fatty acid amides from Echinacea. Bioorg Med Chem Lett 25: 3091-3094.

6. Sharma N, Kumar A, Sharma PR, Qayum A, Singh SK, et al. (2018) A new clerodane furano diterpene glycoside from Tinospora cordifolia triggers autophagy and apoptosis in HCT-116 colon cancer cells. J Ethnopharmacol 211: $295-310$.

7. Sultan P, Jan A, Pervaiz Q (2016) Phytochemical studies for quantitative estimation of iridoid glycosides in Picrorhiza kurroa Royle. Bot Stud 57: 7.

8. Liu XY, Niu X, Feng QJ, Yang XZ, Wang DW, et al. (2016) A new biocompatible microemulsion increases extraction yield and bioavailability of Andrographis paniculata. Chin J Nat Med 14: 683-691.

9. Bhandari U, Ansari MN (2009) Ameliorative effect of an ethanol extract of Embelia ribes fruits on isoproterenol-induced cardiotoxicity in diabetic rats. Pharmaceutical Biology 47: 669-674.

10. Hannan JM, Marenah L, Ali L, Rokeya B, Flatt PR, et al. (2007) Insulin secretory actions of extracts of Asparagus racemosus root in perfused pancreas, isolated islets and clonal pancreatic beta-cells. J Endocrinol 192: 159-168.

11. http://www.rroij.com/open-access/a-review-on-pharmacological-profile-ofwithania-somnifera-ashwagandha-6-14.pdf

12. Abbaszadegan A, Gholami A, Ghahramani Y, Ghareghan R, Ghareghan M et al. (2016) Antimicrobial and Cytotoxic Activity of Cuminum Cyminum as an Intracanal Medicament Compared to Chlorhexidine Gel. Iran Endod J 11: 4450 .

13. Shiwakoti S, Poudyal S, Saleh O, Astatkie T, Zheljazkov VD (2016) Method for Attaining Caraway Seed Oil Fractions with Different Composition. Chem Biodivers 13: 695-699. 